\title{
Marianne North e Margaret Mee: artistas botânicas no Brasil pós-colonial
}

\author{
Lívia Segadilha $^{1}$ \\ Renata Gonçalves Gomes ${ }^{2}$
}

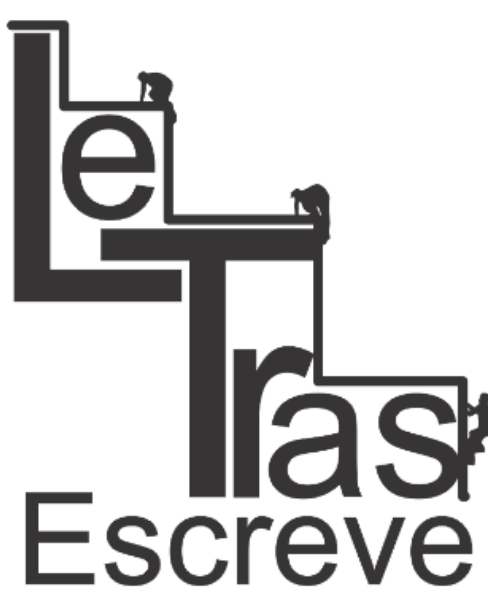

(ISSN 2238-8060)

Resumo: Marianne North e Margaret Mee, pintoras do meio-ambiente natural do Brasil, têm seus diários publicados em livros como $A$ viagem ao Brasil de Marianne North 1872-1873 e Flores da Floresta Amazônica: a arte botânica de Margaret Mee. Salvaguardados os diferentes períodos e contextos em que ambas viveram, North e Mee têm similaridades em relação ao seu trabalho como pintoras, além de seus pontos de partida e chegada: Inglaterra e Brasil, respectivamente. A partir disso, esse artigo levantará questões sobre classe e etnia interseccionadas à questão de gênero, comum aos trabalhos de ambas as autoras em seus diários de viagem. Portanto, esse artigo tem como objetivo investigar a relação entre colonizador-colonizado, Inglaterra-Brasil, através da documentação nos diários de North e Mee. A posição de ambas como viajantes e documentaristas no Brasil se torna relevante a partir do momento em que a investigação entre colonizador-colonizado é feita através do olhar estrangeiro feminino.

Palavras-chave: Marianne North; Margaret Mee; Literatura Comparada; Mulheres Viajantes; Estudos Culturais.

Abstract: Marianne North and Margaret Mee, English painters of the Brazilian natural environment, have their travel journals published in books such as A viagem ao Brasil de Marianne North 1872-1873 and Flores da Floresta Amazônica: a arte botânica de Margaret Mee. Safeguarded the different times and contexts of both authors, North and Margaret have similarities regarding their work as painters, and their common departure and arrival places: England and Brazil, respectively. Bearing that in mind, this article will point out issues regarding class and ethnicity intersected with gender, raised by both authors in their travel journals. Therefore, this article aims at investigating the relationship between colonizer-colonized, England-Brazil, through the documentation in journals by women travelers, i.e., North and Mee. Their position as travelers and documenters in Brazil is relevant for the comprehension of the relationship colonizer-colonized through women's perception.

Keywords: Marianne North; Margaret Mee; Comparative Literature; Women Travelers; Cultural Studies.

\section{Introdução}

Marianne North e Margaret Mee viajaram pelo Brasil póscolonial em séculos distintos em busca de belvederes naturais para

\footnotetext{
${ }^{1}$ Bacharel em Letras - Língua e Literaturas em Língua Inglesa pela UFSC.

2 Docente na Universidade Estácio de Sá. Doutoranda em Literaturas em Língua Inglesa pela UFSC.
}

https://periodicos.unifap.br/index.php/letras

Macapá, v. 6, n. I, Io semestre, 2016. 


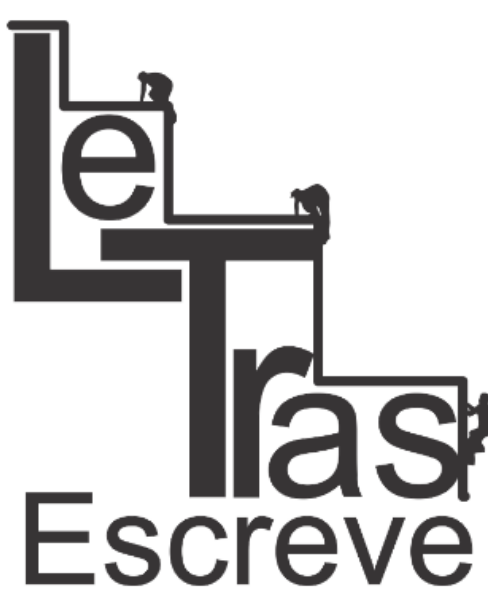

(ISSN 2238-8060) serem pintados. Donas de técnicas diversas como aquarela, acrílico, nanquim e óleo, por exemplo, ambas têm em seus oeuvres não somente obras de arte que representam a natureza brasileira, como também relatos de viagem que revelam o contexto sócio-político e ambiental brasileiro do período pós-colonial. Salvaguardadas as diferenças de época do Brasil em que cada artista viveu, North no século XIX e Mee no século XX, ambas são pintoras inglesas com objetivos similares, qual seja, o de retratar o Brasil através de pinturas e relatos em diários. Tendo em vista as similaridades de ambas as artistas e as diferenças de época que cada uma vivenciou no Brasil pós-colonial, tem-se como objetivo principal para este artigo refletir sobre a seguinte pergunta: como Marianne North e Margaret Mee revelam, em seus diários, as questões políticas e sociais do Brasil pós-colonial em termos de etnia, classe e gênero? Para a reflexão de tal pergunta, será desenvolvido o conceito de "zona de contato", dentro de um contexto pós-colonial, cunhado por Mary Louise Pratt (1992), a fim de melhor compreender a relação de poder entre colonizador (Inglaterra) e colonizado (Brasil) a partir da vinda de North e Mee como exploradoras de paisagens e viajantes.

\section{Marianne North: mulher audaciosa}

Marianne North viveu entre os anos de 1830 e 1890, filha de uma família aristocrata inglesa. North começou a viajar com seu pai quando tinha 17 anos e após a morte de sua mãe, estabeleceu-se solteira para cuidar de seu pai (BANDEIRA, 2012, p.11), com o qual dividia o amor pela botânica e por viagens. Mas foi depois da morte dele, em 1869, que North começou a viajar de navio através dos oceanos, até chegar ao Brasil em 1872. Na Inglaterra do século XIX, a era vitoriana apresentava um contexto de preconceitos e de brutais desigualdades de classe e de gênero. Marianne North, ao contrário, preferiu largar os espartilhos que a apertavam em terras inglesas e partir para os trópicos. No texto "Solteironas audaciosas" 
(BANDEIRA, 2012, p.37), há uma referência ao texto de Pratt em que o autor define North e Julia Margaret Cameron como "Spinster Adventuress".

Cameron e North se encaixam no que Mary Louise Pratt chamou de "Spinster Adventuress" (solteironas audaciosas), categoria em que foram inseridas as mulheres vitorianas que, para fugir do confinamento daquele mundo, viravam as costas para a Europa em buscas das "zonas de contato" com nativos na América Latina, África e Ásia. (BANDEIRA, 2012, p.37)

Há de se dizer que tanto o termo spinster quanto a sua tradução literal para o português "solteirona" carregam consigo uma conotação pejorativa que desqualifica a mulher. Não é o caso de se dizer que tais mulheres, e neste caso em análise, North, tenham suas personalidades de exploradoras vinculadas aos seus estados

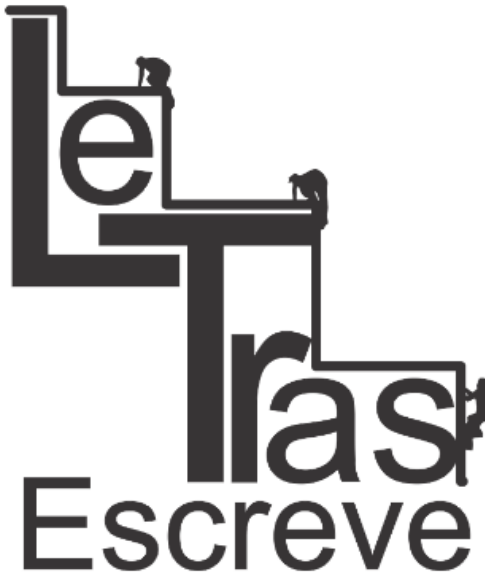

(ISSN 2238-8060) civis, no caso, solteiras. É provável que, se fosse uma mulher casada e com filhos, dificilmente North teria sido uma exploradora durante o século XIX.

Assim, na conotação de Bandeira, North não é considerada uma mulher audaciosa, mas uma "solteirona" audaciosa, o que a coloca em uma posição de derrotada a partir dos valores de uma sociedade opressora e heteronormativa, a qual o autor menciona sem problematizar. A "derrota" no casamento - e o termo "solteirona" reforça isso - desqualifica a mulher, até mesmo quando esta tem feitos profissionais e históricos, além de não considerar outras sexualidades se não a heterossexualidade. Por isso, ao tratar North como uma solteirona audaciosa, Bandeira acaba por vincular seus feitos profissionais ao fracasso conjugal e amoroso. Alexander von Humboldt, por exemplo, dificilmente deve ter sido chamado de "solteirão" em algum texto sobre suas viagens, mesmo nunca tendo sido casado.

De qualquer forma, à parte do estado civil de North, é possível dizer que ela deixou a era vitoriana, que tanto reprimia as mulheres, e foi para uma região em que pudesse vivenciar outra cultura, não 
necessariamente não repressora. Em uma foto ${ }^{3}$ tirada por Julia Margaret Cameron, de 1877, North aparece em Ceilão vestindo uma roupa nada em conformidade com a era vitoriana.

Figura 1 - Marianne North

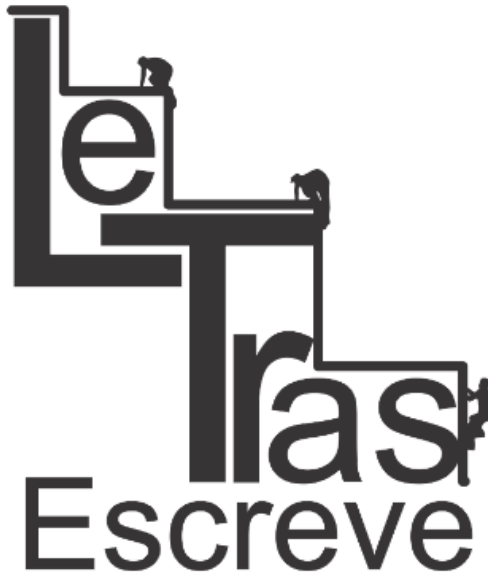

(ISSN 2238-8060)

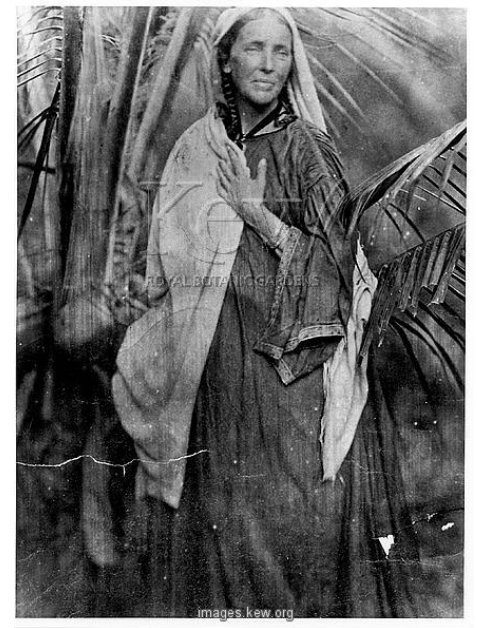

Fonte: Royal Botanical Gardens, Kew.

O vestuário frouxo e sem ornamentos de North em tal foto, revela o contraste da vivência entre a cultura inglesa vitoriana e a dos trópicos. North, no contexto brasileiro em que viveu, podia gozar de mais privilégios do que em sua terra natal. Como mulher, estava livre dos espartilhos e das normas sociais que oprimiam as mulheres. Como visitante, gozava de seu privilégio de ser inglesa e aristocrata, o que fazia com que convivesse, no Brasil, com barões, senhores feudais e mulheres da mais alta classe social. Isso fazia com que North observasse com distanciamento as relações de classe e étnico-raciais do Brasil pós-colonial.

À época em que chegou ao país, a abolição da escravatura já estava sancionada pela Princesa Isabel, porém, como se sabe, o processo de desescravatura perdura até os dias atuais. Nos relatos de North, há muitas referências aos escravos e escravas, na maior parte das vezes, com um posicionamento político muito restrito

\footnotetext{
${ }^{3}$ Tal foto se encontra no livro de Bandeira (36) e é facilmente encontrada na internet através de sites de busca. Os direitos sobre a imagem são do Royal Botanic Gardens, Kew.
}

\section{https://periodicos.unifap.br/index.php/letras Macapá, v. 6, n. I, Io semestre, 2016.}


àqueles que provém de uma classe privilegiada. Não existe, nos relatos de North, uma problematização das questões étnico-raciais e, consequentemente, de classe. Ela goza do seu privilégio de classe e defende a escravatura.

[...] ainda que leis para a emancipação futura desses escravos estejam aprovadas, este será um processo muito gradual, com vinte anos sendo ainda necessários antes de achar-se plenamente realizado. Teria sido melhor, talvez, se os nossos antigos legisladores não tivessem sido tão apressados e tão arrebatados pela ideia absurda de "em cada homem, um irmão". [...] É um erro supor que os escravos não são bem tratados, em todos os lugares os vejo sendo mimados como mimamos animais de estimação e, em geral, estão sempre sorrindo e cantando. (BANDEIRA, 2012, p.159)

North compreende bem os trâmites do processo de

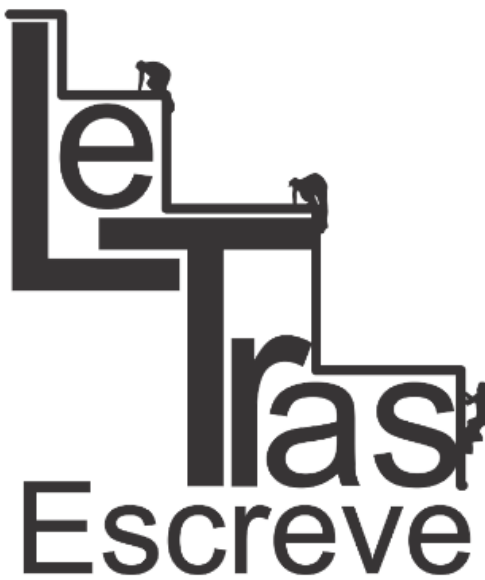

(ISSN 2238-8060)

desescravatura, ao afirmar que a emancipação é um acontecimento gradual e lento. Porém, ao afirmar que esse processo seria demasiado longo, North condena não a demora pela liberação dos escravos, mas a nova sanção de abertura do processo de desescravatura feita pelos legisladores, afirmando que tais escravos têm uma vida plena, assim como animais de estimação mimados. A comparação de North chega a ser grotesca e, vinda de uma mulher branca, estrangeira e aristocrata, evidencia o grande distanciamento entre a sua realidade privilegiada e a realidade dos escravos da época.

Ainda a partir do mesmo excerto é possível compreender a relação de poder estabelecida entre North e os escravos. Para ela, os escravos são comparáveis a animais de estimação, os quais são mimados por ela e por outros iguais a ela. Essa visão turva de North perante a sua realidade destaca a classe social na qual ela se encaixava.

Os problemas sociais da Inglaterra do século XIX eram marcados pela grande diferença de classes, entre proletariado e aristocracia. No Brasil do século XIX, além dos problemas sociais provindos da diferença de classes, a escravatura ainda era muito 


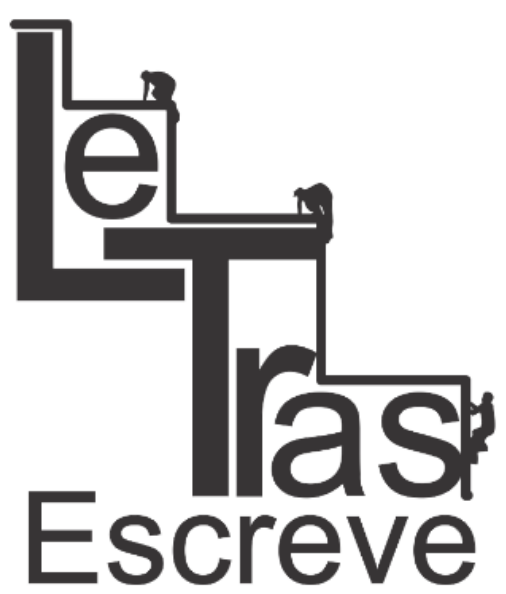

(ISSN 2238-8060) evidente. Sendo North inglesa, além da questão de diferença de classe entre ela e grande parte dos brasileiros, existe também uma relação de poder entre colonizador e colonizado. Mesmo o Brasil não tendo sido colonizado pela Inglaterra, esta foi uma grande potência colonizadora e sua soberania política foi reconhecida desde as grandes navegações. Por isso, é relevante pensar a posição de North não apenas como aristocrata, mas como aristocrata inglesa no Brasil do século XIX, o que a coloca num lugar de poder colonizador.

Propomos pensar as relações de poder entre North e a população local do Rio de Janeiro - exceto suas companhias aristocratas donas de terras - através do que Mary Louise Pratt (1991) conceituou como "zona de contato". De acordo com a autora, as zonas de contato são geralmente espaços sociais nos quais diferentes culturas se encontram e estabelecem relações. Essas relações são assimétricas e realçam a relação dominantesubordinado, como colonialismo e escravidão (1991, p. 4). O contato é estabelecido a partir do distanciamento entre North e os locais, ocorrido, principalmente, por causa da relação assimétrica de classe e também da colonização.

Através dos diários de North, é possível caracterizar a zona de contato estabelecida entre ela e os locais a partir do seu olhar, que se revela preconceituoso sobre as diferenças étnico-raciais. North demonstra, através de seus diários, um estranhamento em relação a mulheres negras, quando as vê no mesmo local em que ela se encontra, o Mercado.

O Mercado era muito divertido e cheio de figuras estranhas. Negras robustas usando blusas bordadas decotadas (soltas), saias espalhafatosas e mais nada, exceto por um lenço vistoso e algumas flores na cabeça. (BANDEIRA, 2012, p.156)

O desconforto sobre as "figuras estranhas" que caminhavam pelo Mercado é representado apenas por uma mulher negra. A diferença étnico-racial, ali, é tratada com o mesmo distanciamento que North tem sobre os escravos, comentado anteriormente. A partir

https://periodicos.unifap.br/index.php/letras Macapá, v. 6, n. I, Io semestre, 2016. 


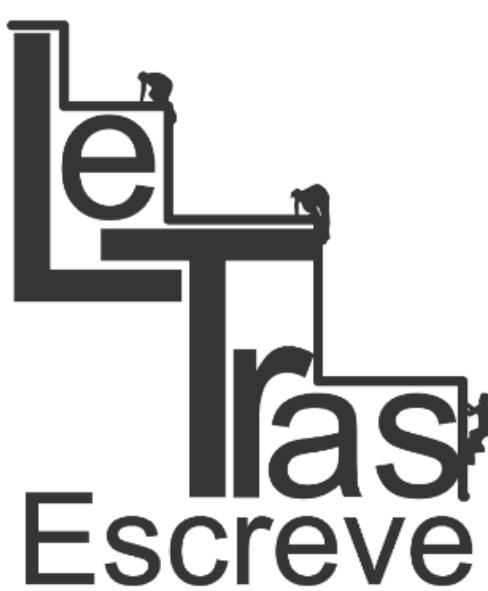

(ISSN 2238-8060) da expressão "figuras estranhas", North caracteriza a mulher negra como a que se veste ao mesmo tempo de forma espalhafatosa e simplória ("saias espalhafatosas e mais nada"), já que em sua visão de aristocrata europeia, um lenço vistoso e flores parecem não ser considerados ornamentos.

Entretanto, interessa perceber que North é, antes, uma estranha se considerarmos o contexto da era vitoriana e as expectativas em relação às mulheres da época e do período póscolonial brasileiro. Porém, no Brasil, ao falar sobre as mulheres negras, North estabelece uma relação de alteridade e não intersecciona a questão étnico-racial com a questão de gênero vivenciada por ela mesma, inclusive ao vestir roupas incomuns para uma "dama inglesa", como naquela foto de 1877. North, apesar de estranha a alguns valores da época, se restringe ao posicionamento de mulher branca, europeia e aristocrata, para quem não parece existir relação alguma com as mulheres negras que caminham no Mercado do Rio de Janeiro.

A partida de North da realidade vitoriana da Inglaterra do século XIX e a sua chegada ao Brasil recém pós-colonial evidenciam questões ligadas a gênero, classe e raça em seus diários. Sendo North uma aristocrata no Brasil e convivendo com similares no Rio de Janeiro, a bruta realidade brasileira da escravidão e da diferença de classes era problematizada por ela apenas a partir de seu olhar distanciado. Ao contrário, North incentivava a escravidão pois não via nela problema algum. Via também as mulheres negras do Rio de Janeiro como exemplos de "figuras estranhas". Assim, as evidências textuais apontadas aqui mostram que a zona de contato entre North e a maior parte da população brasileira era estabelecida a partir de uma relação de poder entre uma mulher aristocrata e branca e a população negra escrava ou muito pobre.

https://periodicos.unifap.br/index.php/letras Macapá, v. 6, n. I, Io semestre, 2016. 


\section{Margaret Mee: A dama das bromélias}

Margaret Mee teve sua primeira expedição pela Amazônia em 1956, aos 47 anos. A partir de então, ela retornou à Amazônia mais quatorze vezes até o ano de 1988, quando faleceu na Inglaterra, seu país de origem, em uma acidente de carro. Essas expedições tinham o objetivo de explorar a floresta Amazônica, para que Mee pudesse pintar algumas plantas em seu habitat natural. $O$ que interessava a Mee não era apenas pintar a planta deslocada de seu ambiente natural, mas o contrário. Desta forma, para ela, a planta estaria em sendo reproduzida em sua íntegra e no seu auge de beleza.

Em cada uma das expedições, Mee não apenas pintava as plantas tropicais, como também escrevia relatos de viagem.

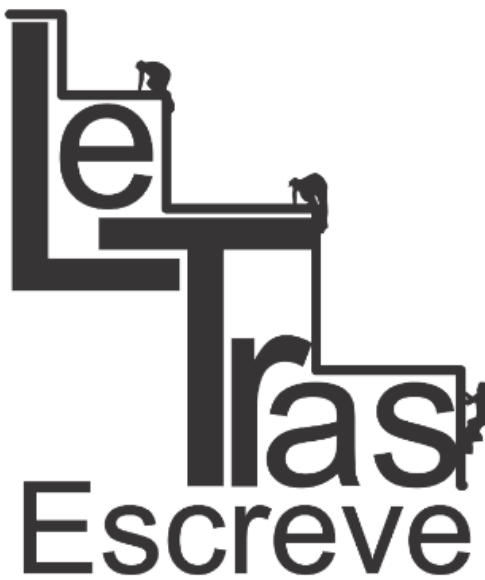

(ISSN 2238-8060) Diferentemente de North, que viveu a maior parte de sua estadia no Brasil urbano do Rio de Janeiro, Mee não detém muito espaço em seus diários para as relações com a população local e suas impressões sobre esta, mas principalmente se preocupa com as questões ambientais da flora e da fauna. Diferente de North, que vivia no Rio de Janeiro, capital nacional à época, Mee viveu boa parte de suas estadias no Brasil dentro da floresta Amazônica, o que Ihe permitia uma relação mais estreita com os animas selvagens, silvestres e plantas, ao invés de com a população local que já era escassa nesse lugar.

Os diários de Mee apresentam descrições do meio ambiente brasileiro com detalhes, além de recorrentes contextualizações referentes aos viajantes exploradores neste território. Mee demonstra, em seus diários, grande domínios teórico, sobre a vegetação local, e histórico, sobre os viajantes exploradores na floresta Amazônica. A relação que Mee estabelece entre ela e a terra em que está é de exploradora-explorada, pois seu objetivo é desbravar a floresta em busca de vegetações específicas. Dessa forma, Mee se identifica com exploradores estrangeiros na América do Sul anteriores a ela, como Charles Darwin, Alfred Russel 
Wallace, Henry Walter Bates, Richard Spruce, Alexander von Humboldt e Robert Koch.

Em seus diários, é possível perceber que Mee estabelece comparações com as conquistas e relatos de antigos exploradores da flora e fauna da América do Sul nos arredores da Floresta Amazônica. Apesar de ter vivido boa parte de sua vida em São Paulo, trabalhando para o Instituto de Botânica, Mee parece se identificar como uma exploradora estrangeira da Floresta Amazônica, assim como Darwin, Wallace, Bates, Spruce, Humboldt e Koch. Em alguns trechos de seu diário é possível perceber que o contato estabelecido com a floresta é marcado por uma relação imperialista.

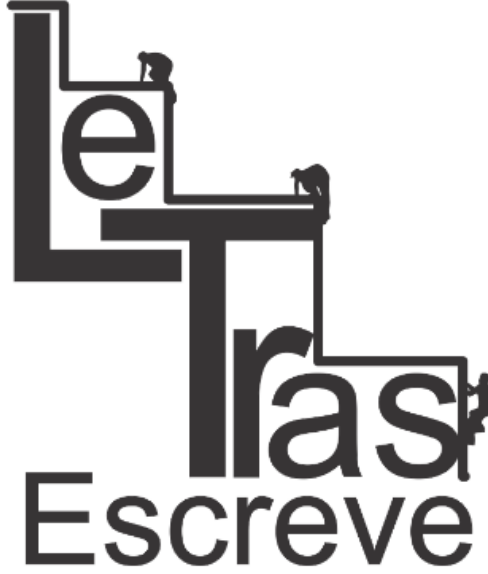

(ISSN 2238-8060)
Eu estava tão impaciente para explorar a região que em minha primeira excursão até um campo próximo encontrei diversas plantas interessantes - uma linda trombeta chinesa branca e amarela, Distictella magnoliifolia. Essa planta foi vista pela primeira vez pelo naturalista Alexander von Humboldt em sua viagem ao Orinoco, em 1800, e somente foi vista novamente na mesma região por Koch, em 1905. (MEE, 2010, p.38)

No trecho acima, é possível perceber que Mee caracteriza a existência da trombeta chinesa a partir do olhar estrangeiro, ou seja, da descoberta colonizadora. Os olhares dos índios nativos da região ou de animais da Floresta à planta trombeta chinesa, para Mee, nunca existiram, pois não há registros anteriores ao de Humboldt. A lógica de que uma planta, animal, terra, só existe - ou é descoberta - a partir do momento em que alguém diz que a descobriu é bastante eurocêntrica, no sentido de que remete à história da colonização e ao poder da escrita (por relatos, cartas, documentos oficiais) ou da catalogação científica. Essa é uma forma de homogeneizar uma outra cultura a partir da sua, ou seja, de fazer com que a cultura dos povos nativos, por não registrar plantas e animais conforme a lógica imperialista europeia, acabe sendo invisibilizada em seu próprio local de origem e vivência. Portanto, a

https://periodicos.unifap.br/index.php/letras Macapá, v. 6, n. I, Io semestre, 2016. 


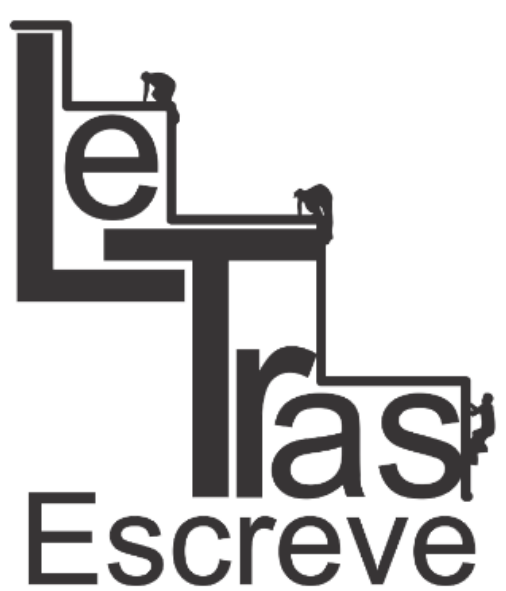

(ISSN 2238-8060) descoberta da trombeta chinesa, como Mee afirma em seu diário, remete à própria História da colonização do Brasil.

Além disso, depois do registro de Humboldt, Mee afirma que tal planta só foi vista novamente por Koch, o que a coloca como a terceira pessoa a ter visto essa planta. Dessa forma, Mee não reconhece uma possível visão sobre a planta feita pelos nativos, já que não há registro científico. Portanto, Mee legitima apenas o conhecimento eurocêntrico e científico, desqualificando qualquer outra forma cultural de convívio entre homem e natureza. Sendo assim, Mee se legitima ao lado de exploradores que ela mesma reconhece como grandes nomes da ciência mundial. De maneira alguma Mee problematiza as questões imperialistas e colonizadoras que tais expedições geraram ao nomearem "descobertas" em terras desbravadas na América do Sul. Segundo Gazzola (2002), essa é uma atitude recorrente em relatos de mulheres exploradoras, cujas representações sobre o outro partem da sua perspectiva eurocêntrica. Esse olhar enviesado confere ao outro, então, um ar de estranheza, fruto da tendência centralizadora de padrões, costumes e tradições do discurso colonial.

Os relatos de mulheres viajantes no Brasil, como pontua North, faz parte do projeto de colonização ao passo que legitima a conquista imperialista, e retoma, inclusive, atores marcantes da história europeia, os primeiros e antes os únicos a escreverem sobre outras culturas. Ao retomar nomes conhecidos, como Humboldt e Koch, por exemplo, Mee se alinha a estes, mas sua passagem é concedida apenas após o reconhecimento de uma história e projeto colonizador iniciado por homens.

Em 1994, a escola de samba do Rio de Janeiro Beija-Flor de Nilópolis teve seu desfile e samba-enredo sob o tema "Margaret Mee, a dama das bromélias". Com tal título é possível ainda problematizar a questão colonizadora de Margaret Mee - e de outros viajantes estrangeiros da Europa em terras Sul Americanas - em relação à apropriação de terras, plantas, animais e povos. No caso,

https://periodicos.unifap.br/index.php/letras Macapá, v. 6, n. I, Io semestre, 2016. 


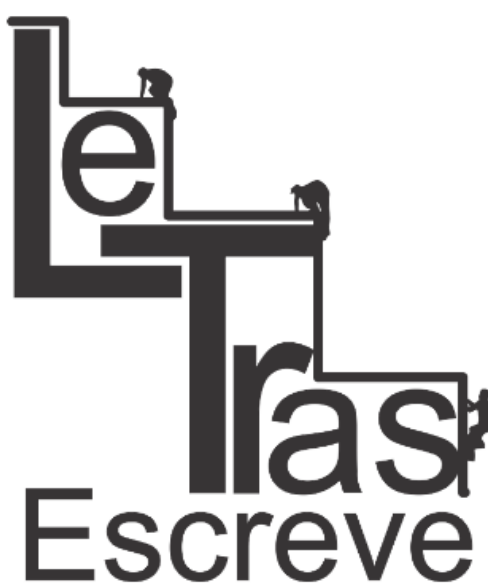

(ISSN 2238-8060) as bromélias são apropriadas por Mee através de uma relação assimétrica de poder, uma vez que a escola de samba a vê como "soberana", conforme a letra do samba-enredo, a quem as bromélias saúdam a chegada: "E ao chegar à "Mata Atlântica"/A "Lady" por bromélias é saudada" (Beija-Flor de Nilópolis, 1994).

É inegável que a representação feita pela Beija-Flor empodera Mee enquanto mulher que, destemida, enfrenta os perigos da mata e não se intimida. Porém, o samba-enredo reinventa as bromélias - uma espécie peculiar da América Latina e da Índia ocidental - por meio da ideia de propriedade, de posse, como se estas tivessem sido conquistadas por uma "Lady" inglesa, Mee. Nesse caso, tal ideia de propriedade (re)produz uma relação assimétrica de dominação (entre colonizadora e colonizada).

Também nos diários, Mee mostra não apenas sua atitude imperialista, como seguidora da lógica eurocêntrica científica e colonizadora, mas também demonstra uma atitude destemida perante a maior floresta do mundo. Mee contava com a colaboração de alguns nativos para se deslocar de canoa através dos rios, mas, apesar de acompanhada durantes os trajetos, a pintora passava a maior parte dos dias sozinha em cabanas ou alojamentos montados na floresta. Alguns dos contratempos da vida na floresta são tratados de maneira leve e bem-humorada em seus diários, como quando, por exemplo, Mee foi picada por um mosquito no Amazonas por volta de 1975: "Enquanto eu colecionava diversos Catasetums em um igapó, fui picada por um marimbondo, porém sem maiores reações. Talvez eu tivesse me tornado imune após tantas picadas." (MEE, 2010, p.108).

Uma mulher que se torna imune a incômodas e dolorosas picadas de inseto enquanto executa seu próprio trabalho traduz, sem dúvida, a imagem de uma mulher forte, empoderada e independente. Porém, essas representações não escapam à lógica do discurso colonial, que legitima o projeto expansionista das

https://periodicos.unifap.br/index.php/letras Macapá, v. 6, n. I, Io semestre, 2016. 
conquistas territoriais, e subalterniza as subjetividades alheias a essa mesma lógica.

\section{North e Mee: Mulheres viajantes}

No texto de "Women's Travel and the Rhetoric of Peril: It is suicide to be abroad", Kristi Siegel reitera o quanto o discurso do perigo às mulheres viajantes está inserido na mentalidade das mulheres, o que muitas vezes as desmotivam a subverter essa ideia. Siegel diz que para o senso comum, aos olhos dos outros, uma mulher que viaja sozinha se coloca em uma posição vulnerável, é desobediente e provavelmente imoral. (SIEGEL, 2004, p. 57) Siegel continua com as perguntas: Qual é a definição de viagem? E quais mulheres estão sendo advertidas? Existe uma grande barreira de gênero no que se diz respeito a viagens de exploração. Essa ainda é uma área predominantemente masculina, tendo as mulheres viajantes e exploradoras um espaço muito restrito. Para além das viagens, tais mulheres têm que quebrar paradigmas sociais e subverter suas posições pré-estabelecidas na sociedade patriarcal ocidental.

Ambas Marianne North e Margaret Mee subverteram o papel da mulher na sociedades inglesas e brasileiras dos séculos XIX e $X X$, cada uma em seu contexto histórico, político e social. North, viajou sozinha para o Brasil de navio em busca de belvederes no Rio de Janeiro para pintar. Dentro de seu contexto no Brasil, North revela em seus diários uma grande diferença de classe e étnicoracial com a maior parte da população com a qual convivia no estado fluminense. Mee, por suas quinze expedições à floresta Amazônica, também subverteu o papel da mulher pré-estabelecido ainda pelas sociedades modernas da segunda metade do século XX. Porém, no Brasil, a partir de uma análise pós-colonial é possível entender alguns trechos do diário de Mee como expressões eurocêntricas colonizadoras. 
De qualquer forma, ambas as artistas botânicas têm seus trabalhos reconhecidos como pintoras, escritoras e viajantes. Suas viagens ao Brasil e suas impressões reladas em seus diários expressam relevantes contextos do país e ressaltam a importância do estudo interdisciplinar de autoras Inglesas no Brasil a partir de uma leitura pós-colonial e de gênero.

\section{REFERÊNCIAS BIBLIOGRÁFICAS}

BANDEIRA, Julio. A viagem ao Brasil de Marianne North 1872-1873. Rio de Janeiro: Sextante Artes, 2012.

GAZZOLA, Ana Lúcia Almeida Gazzola. Letters from brazil: travel writing and the female gaze. Ilha do Desterro, Florianópolis, n. 42, p.129-142 jan./jun. 2002.

MEE, Margaret. Flores da Floresta Amazônica: a arte botânica de Margaret Mee. Rio de Janeiro: Escrituras, 2012.

PRATT, Mary Louise. Imperial Eyes: Travel Writing and Transculturation. New York: Routledge, 1991.

SIEGEL, Kristi. Gender, Genre and Identity in Women's Travel Writing "Women's Travel and the Rhetoric of Peril: It is suicide to be abroad”. New York: Peter Lang, 2004, p. 55-72.

Recebido em 30/07/2016. Aprovado em 16/08/2016. 